\section{Analysis of Emerging Practices in Globalizing Instructional Materials}

\section{by David P. DeBry Sr.}

Since the end of the Cold War, international decisions and forces have fostered a free market economy and facilitated expansion for corporations into new markets (Marquardt, 1995). In addition, new technologies, especially the Internet, allow anyone with access to those available technologies to have a global Web presence and communicate simultaneously. Merely placing a Web page on the Internet could be deemed as having "gone global," because anyone in the world can access it through the Internet. These factors, and others, have brought human societies throughout the world closer together in time and space and have fostered globalization.

Along with the expansion into new markets, globalization has affected all areas of the global corporation in ways unforeseen even a decade ago. This worldwide expansion affects human resource departments and the creation and design of instructional materials, including those used in corporate training. Merrill Lynch reported in a recent survey that the global training market would total $\$ 300$ billion in 2000 , and $\$ 365$ billion by 2003 (Maloy, 2000). Also, at a 1998 American Society for Training and Development symposium held in Beijing, most of the U.S. companies in attendance identified three priorities, one of which was customizing training to the local culture (McCain, 1999). In addition, Rhinesmith (1993) reported that there are 12 areas of global human resource development important to being successful in a global market, 2 of which relate to global training. As witnessed by these and other statements, and given the present level of global corporate expansion, the need to create cross-cultural, instructional materials, and adapt current materials to other cultures, has become a necessity (Abernathy, Allerton, Barron, \& Salopek, 1999; Laroche, Bing, \& Bing, 2000). Instructional designers and other creators of instructional materials are now faced with the task of creating and adapting their materials to other cultures, taking into account language and cultural differences (Hites \& Fisher, 1984). This task of adaptation includes corporate training, Web sites, online courses, and other instructional materials tailored to the needs of international customers and employees of these multinational firms.

The globalization of instructional materials goes beyond just translation, as many other factors are involved (Laroche et al., 2000; Schwartz, 2001). Even before being translated, instructional materials must be prepared to be translated and adapted to specific cultures. Also, after the instructional materials have been designed and developed, and where applicable, those implementing the training need to gain the appropriate cross-cultural communication skills for presenting the training to members of other cultures (Kemper, 1998; Rhinesmith, 1993).

This article summarizes findings of my dissertation, the full text of which can be accessed at http://www.daviddebry.com/ (click on the RESEARCH link). This study examines emerging practices in globalizing instructional materials at seven different global companies, all based in the United States. The research data came from interviews, artifact collection, and minimal observation. Twenty-one different individuals from 10 different departments in these companies took part in the research, which was based on the assumption that additional issues and processes must be addressed in order to design instructional materials for a global audience. The analysis suggests that all of the companies seemed to follow the same general globalization processes, with some differences in practice apparent.

The purpose of the study was to identify emerging practices for globalizing instructional materials. More specifically, it was my intent to identify practices and processes that instructional designers (and others) are following when creating or adapting cross-cultural, instructional materials. In addition, I looked at what the commonalities and differences were of practices and processes between the companies.

\section{Research Questions}

The following research questions support the overall purpose and objectives of this research. These questions acted as a starting point for 
more in-depth discussions, and helped define the boundaries for my research. However, as is typical with qualitative research, I formulated additional questions and refined the original questions depending on inferences drawn from my interviews and observations.

1. What practices are the participant companies following to globalize their instructional materials?

2. What specific processes or procedures do these practices entail?

3. What conscious, as well as (observable) subconscious, actions are performed to complete the globalization processes?

4. What specific tools do instructional designers or trainers use to expedite these processes?

5. How much support do the instructional designers receive from the corporations?

6. What other factors have an impact on the globalization processes?

From these research questions, as well as the review of literature and the pilot-study, both broad and specific interview questions were derived.

\section{Definitions and Issues}

Before reporting what was found in this research, it is important to define what is meant by the terminology used, and some of the basic issues associated with these terms.

Culture. Hofstede (1997) defined culture as "the collective programming of the mind which distinguishes the members of one group or category of people from another" (p. 260) and "derives from oneÆs social environment" (p. 5). In other words, culture can refer not only to race or ethnicity, but also to groups within society, such as the corporate culture, the culture of small-town America, or even the culture of a book club that meets weekly in, say, Lubbock, Texas. However, when referring to culture in this article, and unless otherwise specified, I will be referring to culture in the sense of those (usually defined by geographic border) who speak a common language and have the same values, beliefs, and customs, and especially how a culturally adapted product addresses these groups.

Globalization. The American Heritage Dictionary of the English Language ( online at http:/ / www.dictionary.com/cgi-bin/dict.pl?term=globalization) defines globalization as "making something global or worldwide in scope or application." In business, this term typically refers to the economic and social interaction and integration between cultures, but relates as well to "political, social, cultural and environmental spheres" (Walters, 1997, p. 4). This process of globalization can influence and affect many parts of an organization, including the employees, customers, products, and instructional materials.

Internationalization. The Localisation Industry Standards Association (LISA, http://www.lisa .org/), an international voluntary association developing guidelines for adaptation, has defined internationalization as "the process of designing and implementing a product which is as culturally and technically 'neutral' as possible, and which can therefore easily be localized for a specific culture or cultures" (LISA, n.d.). Because internationalization is a forerunner to localization, it "reduces the time and resources required for the localization process" (LISA). However, internationalization can take place without localization, which often happens when one is creating generic instructional materials, in English, for nonnative English speakers.

Localization. Referring once again to LISA (2001):

Localization is the process of adapting a product (often but not always a software application or hardware component) to meet the language, cultural and other requirements of a specific target environment or market (a "locale"). This process often entails the use of special computer-based tools. (p. 1)

Localization is not just translation, although translation is a major step in the localization process, but includes adding cultural-, politicaland geographic-specific characteristics to materials. It is proposed that localization should take place after a product has been internationalized, to save time and money. 
Translation. Translation is not just changing words from one language to another, but is "the process of reading, understanding, interpreting, rephrasing and delivering an original message, while capturing all of its subtlety and impact, to a new audience in its mother tongue, in the context of its indigenous culture" (Hopkins, 2000, p. 2). Words connote meaning, and when translation occurs, the meaning should be conveyed with as much fidelity as possible. Because translation is a subprocess of localization, instructional designers seldom take part in it directly, but should be aware of the issues involved.

\section{Globalization, internationalization, and localization}

Globalization refers to the whole process of an institution's moving into a global market, and denotes changing business practices, but also implies the adaptation of instructional materials. It is estimated that when materials are first internationalized, and then, if appropriate, localized to each specific target culture, the localization phase will take about half as much time and cost about half as much money as when localization is attempted without first internationalizing (Fry, 2000). Internationalization and localization deal specifically with instructional design, and are carried out, to some degree, during phases of that process. They are subprocesses of globalization.

One of the commonest examples to illustrate internationalization and localization is date formats. In America, dates are expressed as $\mathrm{mm} / \mathrm{dd} / \mathrm{yy}$ (month, day, year), but in many other countries of the world, the month and day are switched to become $\mathrm{dd} / \mathrm{mm} / \mathrm{yy}$, and sometimes even dd.mm.yy. These conventions can even vary within cultures; for example, the United States military uses $\mathrm{dd} / \mathrm{mm} / \mathrm{yy}$. For some dates, such as 01/23/71 (January 23, 1971), there is little or no confusion. Because there is no 23rd month, it is clear which numbers correspond to the month and day. However, if the date were given as $7 / 9 / 70$, it would not be clear to a global audience whether the date was the ninth day of the seventh month, July 9, 1970 (United States), or the seventh day of the ninth month, September 7, 1970 (other parts of the world). Therefore, in an internationalized version, a generic date format may be adopted (such as writing out the date: 24 April 1941), or a blank placeholder may be created to accommodate culture-specific date formats in each of the localized versions.

Globalization, internationalization, and localization are occasionally written as G11N, I18N and L10N, referring to the number of letters between the first and last letters of each word.

\section{Method}

\section{Sample population}

Initially, I contacted 45 people at 15 different companies. This list was narrowed to 21 participants, from 10 different departments, at 7 companies. The list was narrowed to 7 because some of the companies (or departments of those companies) I contacted were not globalizing their instructional materials, even though their company had a global presence. Generally, I was impressed with the people I talked to and how even those with extremely busy schedules were willing to allow time to talk with me, to make appointments, or to put me in contact with the correct people.

The final set of participants came from four computer or software companies, two service companies, and one nonprofit organization. I wanted to interview anyone who was involved in the globalization of the instructional materials. Initially, I contacted instructional designers, asking them if they were involved in this process, and if so, could I interview them. However, as I began talking to people, I found that there were more occupational categories than just instructional designers that were involved in globalization. I discovered that it was best to explain what I wanted to know, and then ask my initial contacts who else was involved in such activities and who could give me more data. I ended up interviewing seven instructional designers and developers, four editors, three training-project managers, two project managers, one product manager, one senior manager, one localization project manager, one subject matter expert, and one marketing direc- 
tor. Each person was contacted by phone, with a follow-up e-mail message, or solely through email. It was a long process getting contacts and confirming appointments, including phone calls and e-mail messages (back and forth) every day for almost two months.

\section{Rationale}

The participant companies were chosen in a purposive manner with five criteria, or strategies, in mind. (a) First, some were chosen because they were considered leaders in the field of globalization. This status was determined by discussions and presentations at the LISA conference I attended, and through a review of the literature. (b) Second, it is sometimes difficult to gain entry to corporations and their processes because of confidentiality and time constraints. Therefore, I contacted a number of firms that employed Utah State University Instructional Technology alumni or those who had connections to the program. I counted on these individuals being more willing to help, or being able to put me in contact with someone who would help. This approach was successful, and all of the companies contacted had a connection to the Instructional Technology program at Utah State University, although I did not always end up interviewing graduates of the program. (c) A third rationale for choosing these specific companies was to obtain a range of the types of instructional materials being globalized. (d) A fourth reason was to study the broad range of experience that each company possessed in this process. For example, at one company, this project was its first attempt at globalization, while others had been globalizing their materials for more than 10 years. (e) A fifth and last reason for choosing these companies was to gain different perspectives on practices and processes. One company gave an outward-to-inward perspective, while the others gave an inward-to-outward perspective. These strategies were successful: I gained entry to all of the companies I contacted and desired to work with.

\section{Description of companies}

As a precondition to conducting this research, my contacts asked that I not identify the companies or their employees by name. Therefore, in order to help the reader contextualize the findings, I have given pseudonyms to the participant companies. Although the pseudonyms are fictitious, in a general way they do reflect the type of business each company is involved in.

Universal Software. Universal Software is a large software developer with close to 50,000 employees in more than 50 countries. More than half of its revenue is derived from overseas sales. It is also considered a leader in globalization, internationalization, and localization practices. For three days I interviewed, on site, two instructional designers, two editors, one localization project manager, one subject matter expert, and one product manager. All of those interviewed at Universal Software were involved in creating the training materials that taught people how to use their software.

OmniTech. OmniTech is a major computer hardware manufacturing company with close to 80,000 employees in almost 50 countries. It receives more than half of its revenues from outside the Americas. I interviewed, on site, two training project managers, one contract instructional designer, and later, by e-mail, one project manager who was overseas. The department that all of these interviewees worked for provided training to other employees about company policies and benefits.

Worldwide PC. Worldwide PC is a leading PC and PC-components manufacturer with almost 20,000 employees in offices in a number of different countries. I interviewed, through several e-mail exchanges, an American manager who was on an extended assignment overseas. He was a training project manager who was involved with a division that creates soft-skills training for its employees. This manager had an extensive background managing and creating training for other cultures.

World Service. World Service is a nonprofit organization that provides services to millions of people world-wide, more than half of whom are located outside the United States. I contacted 
five people from three different departments. Three were interviewed by phone, while the other two were interviewed in person, with follow-up e-mail exchanges. One department provides training materials to individuals who take care of company facilities around the world. Another department provides instructional materials to those carrying out personal research tasks, and the last department acts as a middleman between the development and translation of the instructional training materials.

Global Consulting. This "big-five" consulting firm has close to 100,000 employees in nearly 100 countries. I interviewed, by phone, a senior manager responsible for part of the training and education division. This manager oversaw, and was personally in touch with, the globalization process, and understood how it was carried out. This division trains employees in the different consulting areas it specializes in.

Management Solutions. Management Solutions provides management software solutions to service companies, and although it has had offices overseas since 1991, with more than 2,000 global employees, it has just recently started globalizing the instructional materials that accompany its software. I interviewed, by phone, one of the project managers for the division that creates the training for the software. He is a colead on one of the first projects that will be localized, has been directly involved with the process from the beginning, and has been involved in researching how to globalize Management Solutions's training materials.

International Orienters. International Orienters was atypical in some ways. It was not globalizing its instructional materials; instead, it was using international writers from different countries to create instructional materials for English speakers. I interviewed an editor and a marketing director, both over the phone and on site. This company was chosen to give a different perspective on globalization, or what it takes to involve other cultures in creating instructional materials.

Typically, I interviewed only one employee from one department, because many of the companies had only one training department, or only one department that was globalizing instructional materials. However, at World Service, I interviewed employees from three different departments, and from Universal Software, employees from two departments. My purpose was to explore, within each organization and across organizations, the emerging issues in globalizing instructional materials.

\section{Data Collection}

Data were collected by using a number of different methods: interviews, artifact collection, and some observation. Interviews were the primary source of data, with artifacts being almost as important. The interviews consisted of face-to-face interviews where I was on site and talking to the people, telephone interviews, and e-mail interviews where I sent the interviewees a message with the questions and asked them to respond. I conducted on site interviews with Universal Software, OmniTech, World Service, and International Orienters, including at least a part of one day with OmniTech, World Service, and International Orienters, and three days with Universal Software. E-mail interviews were by far the most successful in getting succinct answers, because respondents tended to answer e-mail directly. However, the answers were shorter and less revealing than those obtained in the person-to-person interviews. Before beginning any of the interviews, an informed consent form was read to the participants.

I tape-recorded interviews with 8 of the 21 participants. Each type of interview was geared toward feasibility and obtaining the most relevant information. For example, two of the participants, one from OmniTech and one from Worldwide PC, were overseas and preferred an e-mail correspondence. Aside from e-mail exchanges, each interview typically lasted anywhere from $45 \mathrm{~min}$ to $1.5 \mathrm{hr}$, with most averaging $1 \mathrm{hr}$. During each interview, I asked prewritten questions, and then asked additional questions according to the direction the interview went (except for e-mail). Some of the respondents allowed me to tape-record the in- 
terviews, which were then transcribed, while others preferred that I not record. In these cases I took field notes, which were transcribed at the first opportunity.

Artifacts, a secondary source of data, included those physical and digital items that identified, documented, or explained the globalization process employed in each corporation. Artifacts ranged from internal training materials on company intranets, to paper-based style guides, to design guidelines (sometimes in the form of a job aid), to analysis and evaluation reports and findings. They were given to me with the understanding that I would keep them highly confidential. Therefore, only generalizations have been reported from them. Finally, and as mentioned above, I spent enough time with three companies (at least part of a day each) to collect a minimal amount of observation data, noting additional tasks contributing to the globalization process.

\section{Findings}

This section reports an abbreviated version of findings from the interviews and interactions with the study participants. When possible, quotations or paraphrases from the participants have been used; however, some parts of quotations have been left out or changed to protect the identities of the companies and people. These omissions or changes are identified with brackets.

\section{Nature of target audiences}

Each of the participating companies was developing, either for their employees, for their customers, or for both. Many of the companies were delivering training to educated employees or customers, including some with college degrees or a posthigh-school education, while World Service delivered materials to anyone in general, including some with no formal education.

\section{Nature of instructional materials}

The nature of the instruction ranged from training employees about company-specific procedures, including soft skills (supervision, communications, various aspects of workplace effectiveness, etc.), to training customers how to use products, such as software. All but Management Solutions were delivering their primary materials in a paper-based format, and all but one department at World Service were augmenting these materials with the World Wide Web or in CD-ROM format or an alternative. Most, but not all, of the paper-based materials were delivered in an instructor-led environment.

\section{Globalization track}

Three tracks, or routes, are possible when globalizing instructional materials. With Track 1, materials were delivered in English to nonnative English, or English-as-a-second-language, learners. With Track 2, materials were translated into one additional language, and with Track 3 , materials were translated into multiple languages. A fourth track emerged in this research, which was the translation of materials down the line by local offices (as was sometimes the case with OmniTech and Global Consulting), or by independent vendors rather than the participant companies or departments (as was sometimes the case with Universal Software). Each company and department took different tracks depending on the specific project, although these tracks could change depending on projects and departments. However, all of the companies started with instruction in English as a base, because they are all American-based companies, but also because, as a manager at Global Consulting said, "That's the business language around the world ... English."

\section{Summa ry}

This research investigated the process of globalizing instructional materials. It was based on a review of literature, and data collected from seven companies. More specifically, literature was reviewed, and research conducted, on globalization, internationalization and some localization, areas that focus on delivery of 
products to international and local audiences. Through this research, emerging practices in globalizing materials were identified.

Seven companies were studied, and for the purpose of anonymity, pseudonyms were used. The pseudonyms are Universal Software, OmniTech, Worldwide PC, World Service, Global Consulting, Management Solutions, and International Orienters. These companies included software and hardware providers, service organizations, and education providers. However, I have chosen to present only key findings from the research, first, to answer the research questions, and second, to identify major and minor themes. The numbered research questions are listed, followed by a brief recap of the related findings.

1. What practices are the participant companies following to globalize their instructional materials?

and

2. What specific processes or procedures do these practices entail?

Through the research and data collection, a common framework, or model, arose, which summarizes, in a general sense, the globalization process common to all of the companies. Each company's globalization process fit into this general model. The model shows that all of the companies were globalizing by obtaining input and feedback from members of local cultures.

3. What conscious, as well as (observable) subconscious, actions are performed to complete the globalization processes?

This study produced some observable data in this area, but not as much as was hoped for, because research was conducted on site at only four of the seven companies (Universal Software, OmniTech, World Services, and International Orienters), and because of participant constraints, time spent on site was limited. In addition, very little of the time spent with the four companies visited was spent observing everyday tasks in the globalization process. Most of the time was spent conducting sit-down interviews in a static environment. A last reason for the lack of observable data was the lack of ac- cess to written and digital artifacts. Access was granted to examine a few artifacts, but some of the companies had none, using word-of-mouth communication instead, while others would not allow these materials to be viewed by an outsider because of confidentiality concerns. Those artifacts which I was able to examine included analysis documents, style guides and templates, and evaluation documents. Although I was not able to directly observe the process of globalization in situ, I was able to infer it from statements of people interviewed, and from the few artifacts and observable data made accessible to me.

4. What specific tools do instructional designers or trainers use to expedite these processes?

This research found that tools ranging from paper based to computer based were used to expedite the globalization process. In addition, people were used as resources, or tools, to help in this process. At some companies, job aids had been distributed, or resources were available online on company intranets. Also, computerbased applications were used that could deliver the instructional materials in many cultural environments.

5. How much support do the instructional designers receive from the corporations?

In all cases investigated by this research, upper management had mandated the design and development of instructional materials for a global audience. Beyond this mandate, other structures had been put into place to support the instructional designers, but many had to learn and research processes on their own, or as a group.

6. What other factors have an impact on the globalization processes?

The last research question found a number of specific factors that contribute to, or take place during, the globalization process. These factors included support from the target audience during the instructional design and development process, and awareness of cultural and technical issues. These themes, and others, will now be discussed in more detail. 


\section{Major and minor themes}

Within the findings of this research, five major, and four minor, themes were identified as emerging practices in globalizing instructional materials. Major themes (globalization process, instructor delivered training versus packaged instruction, corporate culture the winner, evidence of administrative support, representatives from target cultures involved in the globalization process) include those that had a direct bearing on the whole globalization process, while minor themes (designers working in the dark, use of integrated software helps, practicing writing for translation, awareness of cultural and technical issues) affected only specific subareas of the process. These themes were apparent in the operations of all of the companies interviewed.

\section{Major themes}

Globalization process. Although the data collection looked at only seven companies, the review of literature showed that many companies with a global presence are involved in globalizing their instructional materials. And although more money is spent on products and services that increase revenue for these companies, care is still taken, and money spent, to ensure that globalized instructional materials, which in many cases accompany products and services, are tailored to either a global or a local audience.

Instructor delivered training versus packaged instruction. A second major theme, one that was only alluded to, but which appears to have lasting impact on and consequences for the future, is the need for further adaptation as globalized materials move to different types of media. In all but one case, the instructional materials identified in this research were delivered primarily in an instructor-led environment, and the designers relied heavily upon local instructors to adapt training to local populations. However, as instructional materials move to more of a packaged delivery medium, such as CD-ROM, digital video disks, or the Internet, and away from an instructor, more internationalization, localization, or both will be required. It is assumed that this move will require a better understanding of, and stricter adherence to, globalization processes. Otherwise, more mistakes and problems will occur.

Corporate culture-the winner. A third major theme was that each of these companies was faced with the issue of resources versus reach, or how far corporations should go to accommodate cultural issues of other countries. In all of the cases, when values came into conflict, corporate culture won out over local preferences, because time and resources were factors. For example, in three of the companies (OmniTech, one department at World Service, and Global Consulting), internationalization, in a pure sense, never took place, although these companies were aware of cultural issues and tried to design with them in mind. Also, at least three of the companies conducted very little front-end analysis to assess needs, audience characteristics, and training environments, but instead decided arbitrarily what the end user needed and how the instructional materials should be designed and developed.

Evidence of administrative support. The fourth major theme that emerged from the interviews was the prevalence of managerial awareness and team support. Persons designing instruction for a global audience found it helpful to have managers or team members with international experience, who could give guidance and answer questions. These team members or managers did not necessarily need to be from the target culture, but needed only to have knowledge of the globalization process and intercultural communication skills. Frequently, this background came from earlier international assignments or from working with minority populations in a region or country.

Representatives from target cultures-involved in the globalization process. The last major theme, and this issue relates to the previous one, was the extensive involvement of people from the target cultures, in the instructional design and development process, from the conception, and throughout the entire process of the instruction- 
al design process. This involvement of locals was accomplished by putting a global project management system in place, which included members of the target culture or people skilled in dealing with cultural issues. Assigning locals to teams compensated for the lack of international experience and knowledge of those involved in the creation and implementation of the instructional materials, and minimized potential cultural, technical, or technological mishaps. The importance of such representation by locals can best be summed up with a quote from an overseas manager with Worldwide PC. He said, "The more the design-development process is completed by members of the same cultural background as the target audience, the easier it is to ensure that the content will be understood, well received, effective, and appropriate to the audience."

\section{Minor Themes}

Designers working in the dark. The first minor theme is a corollary of the finding that corporate culture frequently wins out over local culture, and it is that some instructional designers operate under tight deadlines, with little time to investigate needs or to evaluate results. For example, four of those interviewed reported that they frequently did not have a good conception of who their audience was and what their needs were. Their companies just decided how best to design and develop the materials, and expected them to comply. Also, very little postimplementation feedback was received by instructional designers, as is unfortunately the case in much of the training industry, and therefore they did not know how their globalization process might be refined and made better.

Use of integrated software helps. At Universal Software, instructional designers and others were able to transfer globalized documents back and forth, and in a very timely manner, so that feedback could be given on what was written. This editing and communication system was only made possible by using the Microsoft ${ }^{\circledR}$ Office XP Suite and the integrated editing and communication tools that come packaged with it. Communication ran smoothly and docu- ments could be passed around and edited with ease by using the integrated software. That level of communication was mentioned as ideal but not currently implemented in interviews with other companies.

Practicing writing for translation. A third minor theme, which was stressed by four of the participant companies, was the need to write for translation. This practice included writing for the translator so that the document could be translated not only more easily and cost effectively, but also to enhance understanding for the end user. A number of issues, not shown here, were identified that writers should be aware of, and address, while writing for translation.

Awareness of cultural and technical issues. A fourth and final minor theme was touched on in the section on corporate culture winning. It was found that three of the companies, OmniTech, one department at World Service, and Global Consulting, do not internationalize or localize their instructional materials. Instead, materials are currently designed the way management feels they should be designed, and then cultural and technical issues are "taken into account." Taking these issues into account is all that is entailed in their globalization process.

\section{Conclusion}

Despite its limitations, this article, along with the research from which it is derived, provides important information for the field of instructional technology, and particularly for those involved in the globalization of instructional materials. Although guidelines are not set forth, emerging practices are, which designers can now incorporate into their own instructional design process, and test the results.

David DeBry [debry@byu.net]

[http://www.daviddebry.com] is a training representative for Eastman Chemical Company in Kingsport, Tennessee. He received his doctorate from Utah State University where he wrote his dissertation on globalizing instructional materials. 


\section{References}

Abernathy, D., Allerton, H., Barron, T., \& Salopek, J. (1999, November). Storm warning. Training $\mathcal{E}$ Development, 53(11), 38-39.

Fry, D. (2000). The localization industry primer. (Available from the Localisation Industry Standards Association, 7, rte du Monastre, 1173 Féchy, Switzerland).

Hites, J., \& Fisher, W. (1984, December). Modifying course materials for international students. Performance $\mathcal{E}$ Instruction, 7-9.

Hopkins, R, Jr. (2000). A primer for Webmasters, authors and owners. [On-line]. Retrieved November 19, 2000 from http://www.weblations.com/eng/articles/art_1.htm.

Hofstede, G. (1997). Cultures and organizations: Software of the mind (Rev. ed.). New York: McGraw-Hill.

Kemper, C. (1998, February). Global trainingÆs critical success factors. Training $\mathcal{E}$ Development, 52(2), 35-37.

Laroche, L., Bing, J., \& Bing, C.M. (2000, December). Beyond translation. Training $\mathcal{E}$ Development, 54(12), 72-73.

LISA Frequently Asked Questions. (n.d.) Geneva, Switzerland: Localisation Industry Standards Association. [On-line]. Retrieved January 11, 2001 from:http:/ / www.lisa.unige.ch/info/faqs.html

Maloy, T.K. (2000, August 14). Managers must wade through a sea of training options-The IT learning curve expands. Internetweek, 824, 66.

Marquardt, M. (1995, May). How to globalize your training. ASTD INFO-LINE,_9505.

McCain, M. (1999, July). Scaling the great wall. Training $\mathcal{E}$ Development, 53(7), 38-42.

Rhinesmith, S. (1993). A manager's guide to globalization: Six keys to success in a changing world. Homewood, IL: Business One Irwin.

Schwartz, H. (2001). Seven deadly sins of ebusiness globalization: An executive briefing on taking your online business global. Uniscape Globalization Whitepaper. [On-line]. Retrieved September 12, 2001 from http://www.uniscape.com/globalization/whitepaper.html

Walters, S. (Ed.). (1997). Globalization, adult education and training: Impacts and issues. New York: Zed Books. 